\title{
Prognostic Role of Family History in Patients with Triple Negative Breast Cancer
}

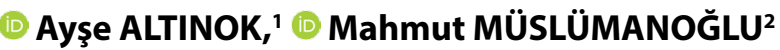 \\ 'Department of Radiation Oncology, Acıbadem Maslak Hospital, İstanbul-Turkey \\ ${ }^{2}$ Department of General Surgery, İstanbul University Faculty of Medicine, İstanbul-Turkey
}

\begin{abstract}
OBJECTIVE
Breast cancer is divided into four subtypes according to the receptor type. Patients with all three of the ER, PR, and c-erb2 receptors negative constitute $20 \%$ of all breast cancer cases. Cases of this group, called triple negative (TN), progress more aggressively than other subtypes. Additionally, familial transmission is more frequent in these patients. Therefore, we planned this study to investigate whether the family history was prognostic on survival in patients with TN breast cancer (TNBC).
\end{abstract}

\section{METHODS}

A total of 158 patients who were diagnosed with TNBC between 1996 and 2017 were retrospectively reviewed. Patients' age, family history, stage, grade, type of surgery, clinical follow-up, adjuvant, and neoadjuvant treatments of the tumor according to TNM system, and their effects on general and disease-free survival were analyzed.

\section{RESULTS}

The median age was 46 years (range 24-82). The mean follow-up period was 72 months (range 10-224). A total of 64 (41\%) patients had family risk for cancers (other than breast and ovarian). A total of 57 (36\%) patients had breast cancer history in their family, 11 (7\%) had ovarian cancer history in their family, and 4 (3\%) had history of both cancers in their family. There was no significant difference between tumor characteristics and family history. In addition, there was no difference between patients with and without family history (breast and ovarian cancer) in terms of local control, disease-free, and overall survival (respectively $\mathrm{p}=0.13, \mathrm{p}=0.11, \mathrm{p}=0.59$ ). The only statistically significant outcome was that diagnosis of a second primary cancer in the opposite breast for no family history group was $2 \%$ compared to $14 \%$ for those with family histories $(\mathrm{p}=0.03)$.

\section{CONCLUSION}

The family history of breast cancer did not affect the prognosis of the patient independently of the degree of consanguinity. These patients should be carefully monitored for the second primary of the opposite breast.

Keywords: Breast cancer; family story; triple negative.

Copyright $\odot$ 2019, Turkish Society for Radiation Oncology

\section{Introduction}

Triple negative breast cancer (TNBC) is a biological subtype characterized by the absence of estrogen, progesterone, and human epidermal growth factor 2 (HER-2) receptors in tumor cells. It constitutes approximately $10 \%-15 \%$ of all breast cancers. $[1,2]$ It has worse prognosis than other biological subtypes.[3-5] 
The prognostic factors identified to date include stage, grade, and lymph node involvement, as in other biological subtypes. However, recent studies show that prognosis is more related to molecular and genetic structure than to these factors.[6,7]

The BRCA gene mutations are frequently detected in "basal like" type breast cancer.[8] However, these gene mutations may be detected in TNBC too. Phenotypic features basal like type, which is almost identical to TNBC, has been intertwined with TNBC in clinical practice.[9]

The prognostic location of these gene mutations predicting familial transmission is under investigation. [10] However, these known mutations are not detected in all patients with a family history. At the moment, there is less data indicating whether family history is a prognostic factor, independent of mutations.

In our study, the patients who were treated with the diagnosis of TNBC were investigated for a family history of cancer and breast/ovarian cancer and the relation between relative degree (first-, second-, and thirddegree) and survival rate were analyzed.

\section{Materials and Methods}

A total of 158 patients who were diagnosed with TNBC between 1996 and 2017 were retrospectively reviewed. Age, family history, stage of tumor according to TNM system, grade, surgery types, clinical follow-up, adjuvant, and neoadjuvant chemotherapies, and radiotherapy were recorded. With these data, overall and disease-free survival of the patients was compared according to their family history.

Family history was questioned as to whether there was a history of general cancer (excluding breast and ovarian cancers) in the first-, second-, and third-degree relatives as well as history of breast/ovarian cancer. Relative degree has been defined as follows: first-degree relative: mother, father, and children; second-degree relative: sibling, grandmother, grandfather, and grandchildren; third-degree relative: aunt, uncle, and their children.

Biopsy date was accepted as the date of diagnosis. The time to progression was calculated using the date of the first local recurrence or metastasis, whichever came first.

\section{Statistical Evaluation}

The Number Cruncher Statistical System 2007 (Kaysville, Utah, USA) program was used for statistical analysis. Descriptive statistical methods (mean, standard devi- ation, median, frequency, ratio, minimum, maximum) were used to evaluate the study data. One-way ANOVA test was used to compare three and more groups with normal distribution in the evaluation of the quantitative data, while the Kruskal-Wallis test was used to compare three and more groups that did not show normal distribution. Pearson's chi-square test and Fisher-Freeman-Halton test were used to compare qualitative data. Significance was at least $\mathrm{p}<0.05$. Kaplan-Meier and log rank test were used for survival analysis.

\section{Results}

Data of 158 patients were analyzed. The median age was 46 years (range $24-82$ ), and the mean follow-up period was 72 months (range 10-224). A total of $64(41 \%)$ patients had family history of general cancers, 57 (36\%) patients of breast cancer history, 11 (7\%) patients of ovarian cancer history, and 4 (3\%) patients of both breast and ovarian cancer history. Family history of cancer according to relative degree is summarized in Table 1.

When tumor characteristics were analyzed, 71 (45\%) patients had T1 stage and 76 (48\%) patients had T2 stage. The histological grade of $126(80 \%)$ patients was third. Lymphovascular invasion was not detected in $99(63 \%)$ patients. There were $100(63 \%)$ patients with axillary N0. The clinical and pathological features of the patients are summarized in Table 2 .

A total of 129 (82\%) patients underwent breastconserving surgery. Pathological evaluation of axillary lymph was left at the stage of sentinel lymph node biopsy in $82(52 \%)$ patients. A total of $148(94 \%)$ patients received chemotherapy. Of these, 29 (18\%) were made as neoadjuvant and $119(82 \%)$ as adjuvant. A total of $139(88 \%)$ patients underwent adjuvant radiotherapy. A total of $19(12 \%)$ patients did not receive radiotherapy indication, and $10(6 \%)$ patients were not indicated for chemotherapy. Five (3\%) patients did not receive

Table 1 According to relative degree, family story

\begin{tabular}{lccccc} 
Relative degree & \multicolumn{2}{c}{ Breast cancer } & & \multicolumn{2}{c}{ Over cancer } \\
\cline { 2 - 3 } \cline { 6 - 6 } & $\mathbf{n}$ & $\mathbf{( \% )}$ & & $\mathbf{n}$ & (\%) \\
\hline First & 10 & 18 & & 2 & 18 \\
Second & 11 & 19 & & 3 & 27.5 \\
Third & 32 & 56 & & 3 & 27.5 \\
First and second & 1 & 2 & & 1 & 9 \\
Second and third & 1 & 2 & & 0 & 0 \\
First and third & 0 & 0 & & 1 & 9 \\
First, second, and third & 2 & 3 & & 1 & 9 \\
Total & 57 & 100 & & 11 & 100 \\
\hline
\end{tabular}




\begin{tabular}{|c|c|c|}
\hline Patients & Number & $\%$ \\
\hline \multicolumn{3}{|l|}{ Median age 46} \\
\hline \multicolumn{3}{|l|}{ T stage } \\
\hline$x$ & 1 & 1 \\
\hline 1 & 71 & 45 \\
\hline 2 & 76 & 48 \\
\hline 3 & 9 & 5 \\
\hline 4 & 1 & 1 \\
\hline \multicolumn{3}{|l|}{$\mathrm{N}$ stage } \\
\hline 0 & 100 & 63 \\
\hline 1 & 40 & 25 \\
\hline 2 & 15 & 9 \\
\hline 3 & 3 & 2 \\
\hline \multicolumn{3}{|l|}{ Grade } \\
\hline 1 & 0 & 0 \\
\hline 2 & 10 & 6 \\
\hline 3 & 126 & 80 \\
\hline Unknown & 22 & 14 \\
\hline \multicolumn{3}{|c|}{ Lymphovascular invasion } \\
\hline Negative & 99 & 63 \\
\hline Positive & 40 & 25 \\
\hline Unknown & 19 & 12 \\
\hline
\end{tabular}

any adjuvant therapy. Local recurrence was found in $4(7 \%)$ patients in the group with a family history of breast cancer and in $8(8 \%)$ patients in the group with no family history $(\mathrm{p}=0.33)$. Detection of distant metastasis for the same groups was found in 7 (12\%) patients and $17(17 \%)$ patients, respectively $(\mathrm{p}=0.29)$. As in the family history of breast cancer case, ovarian cancer history in the family did not have any effect on the patient's local recurrence $(\mathrm{p}=0.66)$ or distant metastasis $(p=0.56)$. Cox's regression analysis of the family history with relative degree came out as statistically not significant. The incidence of second primary breast cancer in the opposite breast during follow-up was $8(13 \%)$ and $8(5 \%)$ in patients with and without breast cancer. This difference was statistically significant $(\mathrm{p}=0.03)$.

\section{Discussion}

Familial transmission is common in TNBC.[11] The BRCA mutation is held responsible for approximately $15 \%$ of the cases. There are studies investigating the effect of BRCA mutation on the prognosis of patients. [12] However, there is limited information about how the family history of cancer affects the prognosis of breast cancer.

Occurrence of the disease at a young age and the high histological grade of the tumor are common clin- ical and pathological features of TNBC. In our study, the parameters that determine the aggressive course of the tumor were found parallel to the literature.

The diameter of the primary tumor and the presence of axillary lymph node metastasis determine the stage of the tumor pathologically. Both are prognostic factors for local recurrence and distant metastasis of the disease, regardless of other parameters. [13,14] It is widely accepted that lymphatic metastasis increases with the increase in tumor diameter, and this increases the risk of distant metastasis and impairs the prognosis.[15] Tumor diameter and axillary lymph node metastasis rates vary depending on the molecular subtypes. The common opinion is that the Her-2 positive and the primary tumor diameter in TNBC are larger than the luminal types.[15] However, in their study of the clinicopathological evaluation of 15,204 patients with breast cancer, the National Comprehensive Cancer Network reported that $86 \%$ of the patients in the TN group $(n=2569)$ were defined as stage T1-T2 at the time of diagnosis.[11] The fact that these women, most of them African American, have small tumors may be considered as a racial factor. In our study, $93 \%$ of all cases were $\mathrm{T} 1$ and $\mathrm{T} 2$ too.

Axillary lymph node metastasis occurrence is the highest in luminal B group patients, and it is seen in Her-2 positives more than other subtypes.[16,17] Thus, the development of distant metastasis without axillary metastasis in the more aggressive trending TNBC may be explained by the fact that the spread is hematogenous, not lymphogen. In our study, axillary lymph node metastasis was not detected in $63 \%$ of the patients.

The incidence of family breast cancer in TNBC varies between $5 \%$ and 25\%.[18] This difference is generally thought to be between races. Whereas the prevalence of breast cancer in the family was found as 5\% in TNBC in a study in carried out in China, Breast Cancer Surveillance Consortium, in a study carried out in the USA among a population of mostly non-Hispanic patients, found the rate as $22 \% .[19,20]$ In our study, this rate was $37 \%$ for a family history of breast cancer.

A few studies evaluate whether family history is an independent prognostic factor or not for overall survival. One of them is the nomogram study that is performed to determine predictive features in TNBC. In this study, family history, histological grade, plasma tumor markers, and tumor localization were found to be independent prognostic factors.[21] This is explained by the negative effect of BRCA-1 mutation, which also increases the frequency of family history in TNBC.[21, 22] However, the prognostic value of BRCA-1 mutation in breast cancer is still unclear.[23-25] 
In our study, there was no difference in terms of known prognostic factors (age, Tstage, Nstage, histological grade, etc.) in patient groups with and without family history. Therefore, statistically, it was appropriate to evaluate the family history as a prognostic factor. However, the absence of first- or second-degree relatives of some patients reduces the reliability of the data. In addition, genetic panel studies for biological subtypes were not available in our study. In patients with no known genetic mutations, the independent prognostic value of family history may be more accurate. All these were the limitations of our work.

\section{Conclusion}

As a result, the presence of a family history of TNBC had no effect on the patient's prognosis regardless of the degree of consanguinity. These patients should be carefully monitored for the second primary of the opposite breast.

Peer-review: Externally peer-reviewed.

Conflict of Interest: The authors declared no conflicts of interest.

Ethics Committee Approval: This study was conducted in accordance with local ethical rules.

Financial Support: The authors declared no financial support.

Authorship contributions: Concept - M.M.; Design A.A.; Supervision - M.M.; Materials - M.M.; Data collection \&/or processing - A.A.; Analysis and/or interpretation - A.A.; Literature search - A.A.; Writing - A.A.; Critical review - M.M.

\section{References}

1. Perou CM, Sørlie T, Eisen MB, van de Rijn M, Jeffrey SS, Rees CA, et al. Molecular portraits of human breast tumours. Nature 2000;406(6797):747-52.

2. Carey LA, Perou CM, Livasy CA, Dressler LG, Cowan $\mathrm{D}$, Conway K, et al. Race, breast cancer subtypes, and survival in the Carolina Breast Cancer Study. JAMA 2006;295(21):2492-502.

3. Rakha EA, El-Rehim DA, Paish C, Green AR, Lee AH, Robertson JF, et al. Basal phenotype identifies a poor prognostic subgroup of breast cancer of clinical importance. Eur J Cancer 2006;42(18):3149-56.

4. Carey LA, Dees EC, Sawyer L, Gatti L, Moore DT, Collichio F, et al. The triple negative paradox: primary tumor chemosensitivity of breast cancer subtypes. Clin Cancer Res 2007;13(8):2329-34.
5. Boyle P. Triple-negative breast cancer: epidemiological considerations and recommendations. Ann Oncol 2012;23 Suppl 6:vi7-12.

6. Dent R, Trudeau M, Pritchard KI, Hanna WM, Kahn HK, Sawka CA, et al. Triple-negative breast cancer: clinical features and patterns of recurrence. Clin Cancer Res 2007;13(15 Pt 1):4429-34.

7. Sorlie T, Tibshirani R, Parker J, Hastie T, Marron JS, Nobel A, et al. Repeated observation of breast tumor subtypes in independent gene expression data sets. Proc Natl Acad Sci USA 2003;100(14):8418-23.

8. Lakhani SR, Reis-Filho JS, Fulford L, Penault-Llorca F, van der Vijver M, Parry S, et al; Breast Cancer Linkage Consortium. Prediction of BRCA1 status in patients with breast cancer using estrogen receptor and basal phenotype. Clin Cancer Res 2005;11(14):5175-80.

9. Bidard FC, Conforti R, Boulet T, Michiels S, Delaloge $\mathrm{S}$, André F. Does triple-negative phenotype accurately identify basal-like tumour? An immunohistochemical analysis based on 143 'triple-negative' breast cancers. Ann Oncol 2007;18(7):1285-6.

10. Kennedy RD, Quinn JE, Johnston PG, Harkin DP. BRCA1: mechanisms of inactivation and implications for management of patients. Lancet 2002;360(9338):1007-14.

11. Lin NU, Vanderplas A, Hughes ME, Theriault RL, Edge $\mathrm{SB}$, Wong YN, et al. Clinicopathologic features, patterns of recurrence, and survival among women with triplenegative breast cancer in the National Comprehensive Cancer Network. Cancer 2012;118(22):5463-72.

12. Xie Y, Gou Q, Wang Q, Zhong X, Zheng H. The role of BRCA status on prognosis in patients with triple-negative breast cancer. Oncotarget 2017;8(50):87151-62.

13. Silverstein MJ, Skinner KA, Lomis TJ. Predicting axillary nodal positivity in 2282 patients with breast carcinoma. World J Surg 2001;25(6):767-72.

14. He MY, Rancoule C, Rehailia-Blanchard A, Espenel S, Trone JC, Bernichon E, et al. Radiotherapy in triplenegative breast cancer: Current situation and upcoming strategies. Crit Rev Oncol Hematol 2018;131:96-101.

15. Ihemelandu CU, Leffall LD Jr, Dewitty RL, Naab TJ, Mezghebe HM, Makambi KH, et al. Molecular breast cancer subtypes in premenopausal and postmenopausal African-American women: age-specific prevalence and survival. J Surg Res 2007;143(1):109-18.

16. Van Calster B, Vanden Bempt I, Drijkoningen M, Pochet N, Cheng J, Van Huffel S, et al. Axillary lymph node status of operable breast cancers by combined steroid receptor and HER-2 status: triple positive tumours are more likely lymph node positive. Breast Cancer Res Treat 2009;113(1):181-7.

17. Crabb SJ, Cheang MC, Leung S, Immonen T, Nielsen TO, Huntsman DD, et al. Basal breast cancer molec- 
ular subtype predicts for lower incidence of axillary lymph node metastases in primary breast cancer. Clin Breast Cancer 2008;8(3):249-56.

18. Anderson K, Thompson PA, Wertheim BC, Martin L, Komenaka IK, Bondy M, et al. Family history of breast and ovarian cancer and triple negative subtype in hispanic/latina women. Springerplus 2014;3:727.

19. Song Q, Huang R, Li J, Fan J, Zheng S, Zhang B, et al. The diverse distribution of risk factors between breast cancer subtypes of ER, PR and HER2: a 10-year retrospective multi-center study in China. PLoS One 2013;8(8):e72175.

20. Phipps AI, Buist DS, Malone KE, Barlow WE, Porter PL, Kerlikowske K, et al. Family history of breast cancer in first-degree relatives and triple-negative breast cancer risk. Breast Cancer Res Treat 2011;126(3):671-8.

21. Lin Y, Fu F, Lin S, Qiu W, Zhou W, Lv J, et al. A nomogram prediction for the survival of patients with triple negative breast cancer. Oncotarget 2018;9(63):32108-18.
22. Li CY, Zhang S, Zhang XB, Wang P, Hou GF, Zhang J. Clinicopathological and prognostic characteristics of triple- negative breast cancer (TNBC) in Chinese patients: a retrospective study. Asian Pac J Cancer Prev 2013;14(6):3779-84.

23. Bayraktar S, Gutierrez-Barrera AM, Liu D, Tasbas T, Akar U, Litton JK, et al. Outcome of triple-negative breast cancer in patients with or without deleterious BRCA mutations. Breast Cancer Res Treat 2011;130(1):145-53.

24. Gonzalez-Angulo AM, Timms KM, Liu S, Chen H, Litton JK, Potter J, et al. Incidence and outcome of BRCA mutations in unselected patients with triple receptor-negative breast cancer. Clin Cancer Res 2011;17(5):1082-9.

25. Pierce LJ, Phillips KA, Griffith KA, Buys S, Gaffney DK, Moran MS, et al. Local therapy in BRCA1 and BRCA2 mutation carriers with operable breast cancer: comparison of breast conservation and mastectomy. Breast Cancer Res Treat 2010;121(2):389-98. 